\title{
Comentarios
}

\section{Tendencias sobre democratización y cultura postbélica en El Salvador*}

Las discusiones sobre la marcha del proceso de democratización en nuestro país ocupan, desde hace varios años, una espacio privilegiado tanto en publicaciones especializadas como en los medios de comunicación social. Menos espacio se dedica al examen de los cambios culturales que se han venido operando en El Salvador durante la última década. Las reflexiones que se desarrollan a continuación sistematizan y resumen ideas que, sobre el tema de la democracia y la cultura, el autor ha planteado en otras oportunidades. Asimismo, trata de avanzar algunas conclusiones de carácter provisional acerca de las implicaciones locales de ambos procesos. Para el desarrollo de esta exposición se plantea una serie argumentos, divididos en tres bloques: ( $a$ ) tendencias sobre democratización; $(b)$ cultura postbélica en El Salvador; y (c) democracia y cultura: implicaciones a nivel local

\section{Tendencias sobre democratización}

Ante todo, hay que dejar en claro qué es lo que se entiende por democracia en la actualidad: se trata de un régimen político basado en las elecciones periódicas, la diversidad de ofertas políticas e ideológicas y la participación organizada de la sociedad civil en el quehacer político nacional. Ciertamente, el ideal democrático no se reduce a estos tres elementos, pero sin ellos poco o nada se puede decir acerca de la vigencia de la democracia como régimen político.

Por otra parte, hablar de democracia en El Salvador supone remitirse a los acuerdos de paz, pues es a partir de ellos que el espacio político se abrió al FMLN, que desde ese momento pudo competir electoralmente con los demás partidos legalmente inscritos (especialmente con ARENA). EI proceso de democratización en nuestro país no arranca con la firma de la paz - hay buenos y consistentes argumentos para sostener que dicho proceso se inició a principios de la década de 1980 -, pero es en ese momento en que la democratización obtiene su impulso definitivo. Con la incorporación del FMLN a la vida política legal, se alcanzó un requisito básico de la democracia: el pluralismo ideológico y político; es decir, un escenario político con ofertas de izquierda, centro y derecha, entre las cuales los ciudadanos - sin presiones o coerciones externas - podían elegir. Otro requisito se había alcanzado previamente: las elecciones periódicas, que desde 1982 hasta 1997 — y es seguro que así será en 1999- se han realizado sin mayores obstáculos en nuestro país. Elecciones periódicas y pluralismo ideológico: dos señales claras de que algo -bastante en relación con un pasado caracteriza-

* Texio de la charla titulada "Tendencias sobre democratización y cultura postbélica en El Salvador y sus implicaciones a nivel local", ofrecida por el autor en la Cumbre "Adiestramiento y planificación del desarrollo de Morazán", organizada por la Agencia de Desarrollo Económico y Social de Morazán (ADEL) y celebrada los días 20, 21 y 22 de enero de 1999, en San Francisco Gotera, Morazán. 


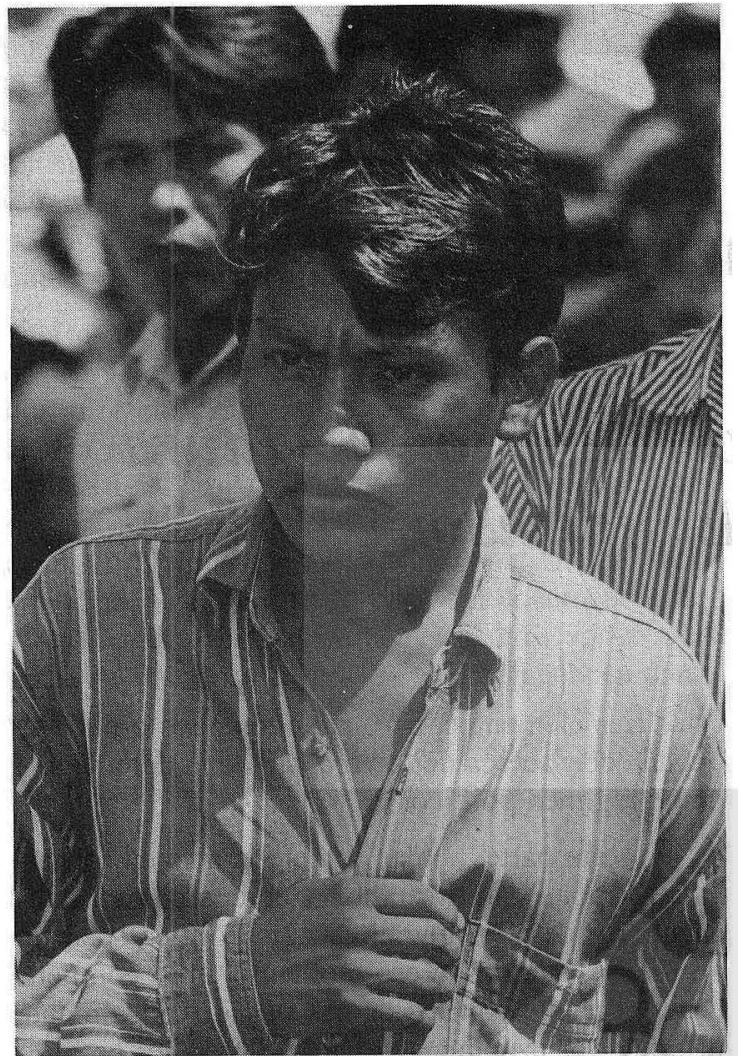

do por el autoritarismo militar y la intolerancia ideológica y política - importante ha pasado en la historia contemporánea de El Salvador.

No basta con elecciones periódicas y pluralismo para hablar de un nivel de democratización satisfactorio. Se requiere de otro componente, que en nuestro país no se ha cumplido a cabalidad: la participación organizada de la sociedad civil. Por un lado, sus niveles de. organización son sumamente débiles (no todos los ciudadanos quieren comprometerse colectivamente); por otro lado, las organizaciones sociales existentes no han logrado establecer una relación fructífera para sus propios intereses con los partidos políticos. Lo anterior ha dado lugar a un divorcio entre la sociedad civil y el sistema de partidos. La primera no se siente representada por este último e incluso desconfía de su capacidad para responder a sus intereses. Varias cosas motivan esta "desconfianza social" en los partidos políticos: su corrupción; la incompetencia de sus miembros; la escasa (o nula) proyección social de su labor; la retórica, vacía de contenidos, del discurso político, etc. Sin duda, uno de los males más preocupantes de la consoli- dación democrática en nuestro país es justamente la desconfianza social ante la política y los políticos. Esa desconfianza refuerza las motivaciones hacia la no participación en los asuntos públicos, aumentando la apatía y el desgano ciudadanos.

Queda en pie el problema de las tendencias de la democratización en el país, es decir, la pregunta por hacia dónde vamos en materia de democtracia. Todo apunta, en primer lugar, a que los males que se atribuyen a los partidos y sus miembros continuarán presentes, al menos hasta que haya un cambio generacional. Esto es, hasta que no emerja una nueva generación de líderes políticos con nuevas ideas y nuevos comportamientos. En segundo lugar, mientras no haya una drástica renovación de la clase política, el malestar social hacia la política y los políticos continuará en aumento, con lo cual seguirán acentuándose las resistencias sociales a participar organizadamente en la solución de los problemas nacionales.

En definitiva, logradas las elecciones periódicas y el pluralismo ideológico y político, el avance de la democratización en El Salvador se juega en la organización y participación de la sociedad civil y en la renovación de la clase política. Si no se avanza en estos dos aspectos, en el futuro inmediato tendremos más de lo mismo. El fortalecimiento del primero de los ejes -organización y participación de la sociedad civil- requiere de un trabajo de educación cívica orientado a alentar las prácticas y los valores democráticos. Se trata de un trabajo cuyos resultados sólo se verán a mediano o largo plazo. El avance en el segundo de los ejes - la renovación de la clase política- depende de al menos dos factores: (a) el agotamiento fisiológico de la actual élite política; y/o (b) el retiro de sus miembros más agotados y el reemplazo por líderes más jóvenes, con metas y ambiciones distintas de las del mero vivir de la política.

\section{Cultura postbélica en El Salvador}

En El Salvador se han producido, en la década de los años noventa, cambios culturales de gran relevancia. Uno de esos cambios tiene que ver con la llamada "cultura política democrática", es decir, con los valores que se asocian a la democracia: tolerancia ideológica, respecto a las opciones políticas de los otros y aceptación de quienes profesan creencias distintas de las nuestras. Esos valores, de ser casi inexistentes en el pasado, poco a poco se han ido arraigando en la mentalidad de individuos 
y grupos. Ciertamente, no se han expandido con igual fuerza en todos los sectores de la sociedad -existen grupos de poder económico y político que añoran el pasado totalitario-, pero sectores significativos de la misma los aceptan y tratan de llevarlos a la práctica.

Un segundo cambio cultural importante se ha operado (o se está operando) en la juventud marginal. Ésta, especialmente la agrupada en las "maras", demanda tanto un espacio territorial propio, así como el reconocimiento de sus símbolos, emblemas y formas de vestir. Estos jóvenes ponen en cuestión ya no la tolerancia política, sino la tolerancia social, es decir, la disposición de quienes nos consideramos "normales" y "decentes" para aceptar un estilo de vida (presente más allá de las prácticas delincuenciales) distinto al que lleva la mayor parte de la población.

Un tercer cambio cultural se está operando en materia de sexualidad. Las prácticas sexuales se están liberando de muchos de los tabués que las acompañaron en el pasado. Las relaciones prematrimoniales, la infidelidad, el lesbianismo y la homosexualidad -que han existido siempre - son condenadas ahora menos que en el pasado, cuando eran motivo de escándalo y reproche incluso por quienes las practicaban. Incluso, el tema del aborto, siempre tan espinoso dadas sus implicaciones morales y médicas, ha dado pie a que se manifiesten posturas distintas de las que tradicionalmente se han manejado.

Un último cambio cultural tiene que ver con lo que se puede llamar "mentalidad urbana". En efecto, cada vez se generalizan más las aspiraciones y valores propios de los habitantes urbanos al conjunto de la sociedad. Este se traduce en un afán por poseer bienes (desde aparatos eléctricos hasta zapatos) usados por los sectores medios urbanos. Pero también en un afán por realizar actividades propias de estos sectores (turismo, profesiones universitarias, etc.). En El Salvador estamos ante un proceso de "urbanización de las costumbres y los estilos de vida" que afecta, en menor o mayor medida, a todos sus habitantes. Este proceso da lugar a marcadas tendencias individualistas y privatizadoras que se manifiestan en la expresión: "lo mío es lo mío (conseguido con mi esfuerzo) y debo disfrutarlo solo".
Lo que no se puede dejar de señalar es que los anteriores cambios culturales no se están operando en el vacío, sino en interacción con patrones culturales heredados de la preguerra: valores políticos autoritarios, un machismo generalizado, el fatalismo propio de algunos sectores rurales y la resistencia al cambio que caracteriza a todos aquellos que creen haber encontrado una situación de seguridad y estabilidad social, laboral o profesional. Todo ello da lugar a una mezcla cultural difícil de analizar y evaluar en todas sus consecuencias; esa mezcla cultural - cuyos componentes sólo pueden ser separados analíticamente- configura buena parte de la identidad del salvadoreño de fines del siglo XX.

\section{Democracia y cultura: implicaciones a nivel local}

El proceso de democratización tiene una implicación fundamental a nivel local: la participación de los ciudadanos en sus municipios. Sin esta participación - la cual tiene que ser activa, responsable y madura-, la democracia en El Salvador no tendrá raíces sociales sólidamente establecidas. Asimismo, los cambios culturales descritos antes tienen también una implicación local importante: afectan la vida cotidiana de los habitantes de El Salvador. Y, precisamente por ello, tienen que ser tratados localmente.

La cultura política democrática tiene que ser fomentada no sólo en cada municipio, sino en cada hogar, escuela y centro de trabajo. El problema de las "maras" tiene que ser abordado por cada municipio, no sólo porque éstas alteran (sea por la violencia o sea por los símbolos) la vida cotidiana de sus habitantes, sino porque muchos de sus miembros suelen tener su familia o amigos en el lugar. El problema sexual también afecta directamente la vida cotidiana de los salvadoreños. Cada uno de nosotros debe tomarse en serio los desafíos que plantea el cambio cultural asociado a la sexualidad. Finalmente, la "mentalidad urbana", al afectarnos a todos, exige un esfuerzo de autorreflexión muy profundo acerca de si nuestras ambiciones y metas se corresponden con lo que en realidad podemos tener. Esta autorreflexión es necesaria, pues ella puede ayudamos a no caer en frustraciones, egoísmos o ambiciones fáciles, pero contrarias a la convivencia solidaria.

Luis Armando González 